\title{
Increased nitric oxide in exhaled air: an early marker of asthma in non-smoking aluminium potroom workers?
}

\author{
M B Lund, P I Øksne, R Hamre, J Kongerud
}

\begin{abstract}
Objectives-To study exhaled nitric oxide (NO) as a marker of airway inflammation caused by potroom exposure, hypothesising that $(a)$ workers exposed to potroom pollutants would have higher concentrations of NO in expired air than control subjects employed at the same plant but working outside of the potroom atmosphere, and (b) that concentrations of exhaled NO in potroom employees might be positively associated with concentrations of fluoride and exposure to dust.
\end{abstract}

Methods-A study group comprising 186 male subjects (aged 24-63 years), employed in the potrooms of one Norwegian aluminium smelter, and 40 comparable control subjects (aged 25-60 years) recruited from the same plant, were examined by measurements of exhaled and nasal concentrations of NO, spirometry, and a questionnaire on respiratory symptoms as a part of an annual health surveillance programme. Estimates of exposure to fluorides and dust for selected job categories were obtained by means of personal samplers carried by the workers.

Results-In the non-smokers, the concentrations of exhaled NO were higher in the potroom workers than in the controls (median (interquartile range) 9.3 (6.215.6) $v 5.7(4.6-8.3) \mathrm{ppb}, \mathrm{p}=0.001)$. The two groups did not differ in spirometry and asthma-like symptoms. Non-smoking potroom workers with asthma-like symptoms had higher concentrations of exhaled NO than those with no symptoms (median (interquartile range) $21.0(19.3-41.4) v 8.5$ (5.9-12.8) $\mathrm{ppb}, \mathrm{p}=0.001$ ), but had comparable spirometric values. In subjects who smoked, the concentrations of exhaled NO did not differ significantly between potroom workers and controls (median (interquartile range) $4.6 \quad(3.3-8.0) \quad v \quad 4.0$ (3.4-5.1) ppb. Exhaled NO was not significantly associated with either duration of employment or routine measurements of dust and fluorides.

Conclusions-Exposure to potroom pollutants is associated with increased concentrations of exhaled NO in non-smoking subjects. Nitric oxide in exhaled air may be an early marker of airway inflammation in aluminium potroom workers. (Occup Environ Med 2000;57:274-278)

Keywords: nitric oxide; occupational asthma; potroom workers
A positive association between asthmatic symptoms and aluminium potroom exposure has been documented in cross sectional and longitudinal studies in workforces ${ }^{1-3}$ and in population studies. ${ }^{4}$ Whether the disorder (potroom asthma) is due to non-inflammatory bronchoconstriction provoked by exposure to airway irritants in the atmosphere of the workplace or is associated with increased bronchial responsiveness and airway inflammation has not been clarified.

Aluminium is produced by electrolysis of alumina $\left(\mathrm{Al}_{2} \mathrm{O}_{3}\right)$ in electrolytic cells (pots). Alumina is reduced by carbon (from the anode) to form $\mathrm{CO}_{2}$ and aluminium. The alumina is dissolved in cryolite $\left(\mathrm{Na}_{3} \mathrm{AlF}_{6}\right)$. There are two types of technology: prebake and Søderberg. In the prebake potroom, the anodes are moulded and baked in a separate plant before they are placed in the pots. In the Søderberg pot, coke paste is placed on top of the anode, and baked by the heat produced by the pot.

Aluminium pot emissions contain a complex mixture of pollutants, and 26 substances to which exposure can occur have been listed. ${ }^{5}$ The emissions from prebake and Søderberg potrooms are principally the same and consist of particulates and gases. Particulates are mainly composed of alumina, carbon dust, and cryolite. Potroom fumes contain gases, such as hydrogen fluoride and sulphur dioxide, and these gases are also absorbed on the surfaces of particulates. Potential causal agents of potroom asthma are fluorides (gaseous and particulates), sulphur dioxide, aluminium oxide, and combinations of these agents.

Endogenous nitric oxide (NO) is thought to play an important part in the pathophysiology of airway diseases. ${ }^{6}$ Increased concentrations of NO have been detected in the exhaled air of patients with asthma ${ }^{7}$ and other inflammatory airway diseases, ${ }^{8-10}$ suggesting that expired NO may serve as a marker of airway inflammation. As it may provide a simple, non-invasive means of monitoring airway inflammation, the measurement of NO in exhaled air has attracted great interest over the past few years. ${ }^{1112}$

Exhaled NO has been studied as a marker of airway inflammation in various groups of patients. ${ }^{7-10}$ However, the method has been applied outside clinical settings only to a limited extent. As aluminium potroom workers are at risk of developing asthma and bronchial hyperresponsiveness, ${ }^{13}{ }^{14}$ a simple, non-invasive means of detecting early signs of airway
Norway

email m.b.lund@

klinmed.uio.no 
inflammation would be particularly useful in this occupational setting.

We aimed to examine whether aluminium plant workers exposed to potroom pollutants would have higher concentrations of $\mathrm{NO}$ in expired air than control subjects employed at the same plant but working outside of the potroom atmosphere, and whether concentrations of exhaled NO in potroom employees would be positively associated with routine measurements of fluoride and dust exposure.

\section{Materials and methods \\ STUDY POPULATIONS}

The study group comprised all male subjects $(n=218)$ employed in the potrooms at one Norwegian aluminium smelter. Of those, 186 subjects $(85 \%)$ participated in the study. Reasons for not participating $(n=32)$ were: declining the invitation $(n=12)$, scheduled time off $(n=10)$, respiratory infections within the past 3 weeks $(n=7)$, illness other than respiratory infections $(n=3)$. The subjects lost to the study were comparable with those participating for mean age (42 $v 40$ years) and duration of employment (17 $v 16$ years). A control group was recruited from employees at the plant's laboratory and mechanical workshop. From a total of 50 male subjects, 40 were included in the study (mechanical workshop, $\mathrm{n}=30$, laboratory, $n=10$ ). Six subjects declined, three were excluded because of recent airway infections, and one because of pneumonectomy (lung cancer). None of the control subjects had ever worked in potrooms, ingot mills, or anode production. As $>95 \%$ of the workforce in the potrooms were men, the study was restricted to male subjects only. People who had had respiratory infections within 3 weeks of the study were not included. The characteristics of the study populations are outlined in table 1 . The study was approved by the Regional Ethics Committee.

\section{STUDY DESIGN}

Since 1985 all potroom workers in the Norwegian aluminium industry have participated in an annual mandatory medical survey in which respiratory symptoms and spirometric measurements have been recorded. In the present study, we had the opportunity to measure exhaled and nasal NO as well as the other tests. The study was carried out in an aluminium smelter in northern Norway during a 2 week period in October 1997. The control group performed the same tests as the study group, and both groups were examined on the same days.

Table 1 Clinical characteristics of 226 aluminium plant workers

\begin{tabular}{lll}
\hline & Potroom workers $n=186$ & Controls $n=40$ \\
\hline Age (y, mean (range)) & $40(24-63)$ & $46(25-60)$ \\
Duration of employment (y, mean (range)) & $16(3-38)$ & $23(4-40)$ \\
Smoking (n (\%)): & $99(53)$ & $30(75)$ \\
$\quad$ Non-smokers & $87(47)$ & $10(25)$ \\
$\quad$ Current smokers & $31(17)$ & $5(12)$ \\
Asthma-like symptoms (n (\%)) & $20(11)$ & $3(7)$ \\
Drugs inhaled (n (\%)): & 0 & 0 \\
$\quad \beta_{2}$ agonists & & \\
$\quad$ Corticosteroids & & \\
\hline
\end{tabular}

QUESTIONNAIRE

All subjects completed a modified version of a self administered questionnaire, validated in a previous study. ${ }^{15}$ Reliability for the various questions had $\kappa$ coefficients ranging between 0.58 and $0.86 .{ }^{15}$ Information about respiratory symptoms (dyspnoea, wheeze, and cough) and smoking habits were recorded. Asthma-like symptoms were defined as the occurrence of dyspnoea and wheezing, apart from during episodes of colds. Use of present medication was recorded. The subjects were classified as current smokers or non-smokers. Information about current job category and duration of employment was also recorded. The potroom workers were familiar with the questionnaire, whereas the control subjects were not.

SPIROMETRIC MEASUREMENTS

Spirometry was performed with a pneumotachograph (Vitalograph, Birmingham, UK) which was calibrated daily by a 1 litre syringe. The measurements were performed in accordance with the guidelines recommended by the American Thoracic Society. ${ }^{16}$ Recorded variables were forced vital capacity (FVC), forced expiratory volume in 1 second $\left(\mathrm{FEV}_{1}\right)$, and $\mathrm{FEV}_{1} / \mathrm{FVC} \times 100\left(\mathrm{FEV}_{1} \%\right)$. The lung function variables were expressed in absolute values and as percentage of predicted, with the reference values of the European Coal and Steel Community (ECSC). ${ }^{17}$ The potroom workers had performed spirometry on previous occasions, whereas most of the control subjects had not. All measurements were carried out by two trained and experienced technicians.

MEASUREMENTS OF NITRIC OXIDE

Nitric oxide was measured with a chemiluminescence analyser (LR 2000, Logan Research, Rochester, UK) adapted for on line recording of NO concentration. The analyser which is sensitive to NO from 1 to 5.000 parts per billion ( $\mathrm{ppb}$ ) by volume, has a resolution 0.3 $\mathrm{ppb}$ and response time $<0.5 \mathrm{~s}$. The analyser also measures $\mathrm{CO}_{2}$ by single beam infrared absorption, and sample pressure and volume in real time. The sampling rate of the analyser was set to $250 \mathrm{ml} / \mathrm{min}$ for all measurements. The analyser was calibrated daily with certified NO mixtures (100 ppb) in nitrogen (BOC Special Gases, Surrey Research Park, Guildford, UK). Ambient NO was recorded twice daily during the study period.

Exhaled and nasal NO measurements were performed in accordance with recommendations outlined in the European Respiratory Society's Task Force Report. ${ }^{12}$ Measurements of exhaled NO were made by slow exhalation (20-30 s) from total lung capacity through a Teflon mouthpiece, against a mild resistance (target mouth pressure of $4-5 \mathrm{~cm} \mathrm{H}_{2} \mathrm{O}$ ) to avoid nasal NO contamination. End expiratory $\mathrm{NO}$ values were measured at the plateau level of the last part of the exhalation curve. Nasal NO was measured with a Teflon tube inserted into one of the nares, while the subjects held their breath, and the value of the last plateau part of the trace was recorded. For both exhaled and nasal measurements, three techni- 
Table 2 Concentrations of particulates and fluorides according to potroom job categories

\begin{tabular}{lll}
\hline & $\begin{array}{l}\text { Total particulates }\left(\mathrm{mg} / \mathrm{m}^{3}\right) \\
\text { (HS 5.0 mg/m } \\
\text { Geometric mean }(S D)\end{array}$ & $\begin{array}{l}\text { Total fluorides }\left(\mathrm{mg} / \mathrm{m}^{3}\right) \\
\left(\text { HS } 1.0 \mathrm{mg} / \mathrm{m}^{3}\right) \\
\text { Geometric mean }(S D)\end{array}$ \\
\hline Pot-operator (Prebake) $(\mathrm{n}=20)$ & $1.58(0.93)$ & $0.38(0.10)$ \\
Pot-operator (Søderberg) $(\mathrm{n}=21)$ & $0.97(0.29)$ & $0.22(0.04)$ \\
Stud pulling ( $\mathrm{n}=10)$ & $0.37(0.12)$ & $0.08(0.01)$ \\
Rodding plant $(\mathrm{n}=20)$ & $0.86(0.36)$ & $0.12(0.05)$ \\
Potroom maintenance $(\mathrm{n}=13)$ & $2.08(2.62)$ & $0.24(0.20)$ \\
Gas cleaning $(\mathrm{n}=15)$ & $4.52(5.07)$ & $2.46(4.10)$ \\
\hline
\end{tabular}

HS=Norwegian hygienic standards; $n=$ number of exposure measurements during 1 year.

Table 3 Pulmonary function in 226 aluminium plant workers

\begin{tabular}{|c|c|c|c|c|}
\hline & \multicolumn{2}{|c|}{ Potroom workers $(n=186)$} & \multicolumn{2}{|c|}{ Controls $(n=40)$} \\
\hline & $\begin{array}{l}\text { Non-smokers } \\
(n=99)\end{array}$ & $\begin{array}{l}\text { Smokers } \\
(n=87)\end{array}$ & $\begin{array}{l}\text { Non-smokers } \\
(n=30)\end{array}$ & $\begin{array}{l}\text { Smokers } \\
(n=10)\end{array}$ \\
\hline FVC $(1$, mean $(\mathrm{SD}))$ & $5.1(0.9)$ & $5.0(0.7)$ & $4.9(0.8)$ & $5.2(0.7)$ \\
\hline FVC (\% predicted)) & $102(14)$ & $102(15)$ & $103(14)$ & $105 \quad(9)$ \\
\hline $\mathrm{FEV}_{1}(1$, mean $(\mathrm{SD}))$ & $3.8(0.8)$ & $3.8(0.8)$ & $3.7(0.7)$ & $3.8(0.5)$ \\
\hline $\mathrm{FEV}_{1}$ (\%predicted)) & $96 \quad(14)$ & $94 \quad(16)$ & $96 \quad(15)$ & $94 \quad(16)$ \\
\hline $\mathrm{FEV}_{1} / \mathrm{FVC}(\%$, mean (SD)) & $77 \quad$ (5) & $75 \quad(8)$ & $76 \quad(8)$ & $74 \quad$ (3) \\
\hline
\end{tabular}

Data are shown as mean (SD) and presented in absolute values and as percentage of predicted value.

cally acceptable measurements were obtained, and the mean of the two closest measurements was reported.

EXPOSURE MEASUREMENTS

As part of the national authorities mandatory surveillance programme of the working atmosphere, measurements of fluorides and particulates are annually carried out in the Norwegian aluminium industry. Potroom workers are randomly selected to wear personal samplers for 8 hour shifts at different intervals (10-20 measurements a year). Eight hour time weighted mean estimates of exposure to total fluorides and particulates in selected job categories were calculated (table 2), representing the exposure during the past years. For job groups with expected low exposure, regular measurements are not carried out. In the present study, levels of exposure could be estimated for 144 out of 186 workers. Some misclassification of exposure will be unavoidable, owing to job rotation.

STATISTICS

All calculations were performed with the SPSS/PC statistical computing package (version 7.5).

Categorical data were compared by the $\chi^{2}$ test. Two independent groups of data were compared by either an unpaired Student's $t$ test or the Mann-Whitney test, depending on whether the data had normal distribution or were skewed. Multiple linear regression analysis was used to detect relations between exhaled NO and relevant independent covariates, controlling for extraneous effects. Values of NO were log transformed before being entered into the regression model, and antilog transformed when presented as results. A value of $\mathrm{p}<0.05$ was consideredto be significant.

\section{Results}

For the entire study group, mean values of FVC and $\mathrm{FEV}_{1}$ were above $90 \%$ of predicted (table 3). There were no significant differences between the potroom workers and the controls, neither did the smokers and the non-smokers differ for spirometric values (table 3 ). In the non-smoking subjects, the concentrations of exhaled NO were significantly higher in the potroom workers than in the controls, while the concentrations of nasal NO did not differ (table 4). In the smokers, the exposed group and the controls had comparable NO concentrations (both exhaled and nasal, table 4).

Non-smoking potroom workers with asthma-like symptoms $(n=12)$ had higher concentrations of exhaled NO (median (interquartile range) $21.0(19.3-41.4) \mathrm{ppb}$, than those with no symptoms $(\mathrm{n}=87)(8.5(5.9-12.8) \mathrm{ppb}$, $\mathrm{p}<0.001$ ), whereas the smokers with asthmalike symptoms did not differ significantly from those with no symptoms. The $\mathrm{FEV}_{1}$ and $\mathrm{FEV}_{1} \%$ were not significantly lower in the subjects with asthma-like symptoms than in those with no symptoms (non-smokers and smokers).

We found no significant correlation between concentrations of exhaled $\mathrm{NO}$ and spirometric values $\left(\mathrm{FVC}, \mathrm{FEV}_{1}\right.$, and $\mathrm{FEV}_{1} \%$ ) in either the exposed group or the controls, or in any of the subgroups (smokers and non-smokers, subjects with asthma-like symptoms, and subjects without symptoms). Controlling for age, smoking, and potroom exposure in a multiple linear regression model, we found that smoking and potroom exposure were associated with respectively a decrease and an increase in exhaled NO ( $\beta$ coefficient -1.8 , SE $1.0, p<0.001$, and $\beta$ coefficient 1.5, SE 1.1, p=0.05). We found no significant associations between concentrations of exhaled NO and routine measurements of total particulates and fluorides or duration of employment.

\section{Discussion}

The main finding of this study was that exhaled $\mathrm{NO}$ concentrations in non-smoking potroom workers were $63 \%$ higher than in non-smoking control subjects recruited from the same plant. The two groups were otherwise comparable for occurrence of asthma-like symptoms and use of $\beta_{2}$-agonists. No subject in either group used corticosteroids. The potroom workers were somewhat younger than the controls (mean age $40 v 46$ years), but concentrations of exhaled NO have not been shown to vary with age. ${ }^{12}$ Although the exhaled NO concentration in the non-smoking potroom workers was not as high

Table 4 Exhaled and nasal nitric oxide concentrations (median (interquartile range)) in 226 aluminium plant workers

\begin{tabular}{|c|c|c|c|c|}
\hline & \multicolumn{2}{|c|}{ Potroom workers $(n=186)$} & \multicolumn{2}{|l|}{ Controls $(n=40)$} \\
\hline & Non-smokers $(n=99)$ & Smokers $(n=87)$ & Non-smokers $(n=30)$ & Smokers $(n=10)$ \\
\hline NO exhaled (ppb) & $9.3(6.2-15.6)^{\star}$ & $4.6(3.3-8.0)$ & $5.7(4.6-8.4)$ & $4.0(3.4-5.1)$ \\
\hline NO nasal (ppb) & $783 \quad(595-926)$ & $633(500-858)$ & $720 \quad(479-920)$ & $729 \quad(563-848)$ \\
\hline
\end{tabular}

${ }^{\star} \mathrm{p}=0.001 v$ controls by the Mann-Whitney test. 
as that found in symptomatic asthmatic subjects, it was comparable to the concentration observed in atopic subjects with bronchial hyperresponsiveness. ${ }^{18}$

In smokers, we found no difference in exhaled NO between potroom workers and controls. This may be because chronic cigarette smoking itself decreases exhaled NO, both in healthy ${ }^{19}$ and in asthmatic subjects. ${ }^{20}$ In mildly asthmatic subjects, the effect of smoking on exhaled $\mathrm{NO}$ is comparable to that of inhaled steroids, and the correlation between exhaled $\mathrm{NO}$ and airway hyperresponsiveness found in non-smoking steroid naive asthmatic subjects is lost, both in steroid treated subjects and in smokers. ${ }^{20}$ This suggests that exhaled $\mathrm{NO}$ as a marker of airway inflammation is of limited value in subjects who smoke. Also, the number of smokers in our control group was small.

The increased concentrations of $\mathrm{NO}$ in exhaled air in potroom workers may reflect a subclinical degree of airway inflammation caused by exposure to pollutants in the work atmosphere. For decades it has been known that subjects working in aluminium potrooms are at risk of developing asthma..$^{1-3}$ It has also been shown that bronchial hyperresponsiveness varies with concentrations of plasma fluorides, ${ }^{14}$ and that after removal from exposure bronchial responsiveness improves considerably. ${ }^{21}$ An increased risk of bronchial hyperresponsiveness and atopy as well as asthma has been shown in children living in the vicinity of an aluminium plant, ${ }^{22}{ }^{23}$ and as the concentrations of pollutants are many times higher inside than outside the potrooms, the effect on respiratory health in children supports the hypothesis that potroom emissions may cause bronchial asthma and bronchial responsiveness in exposed workers. That potroom exposure may induce an inflammatory response in the airways has also been supported by experimental work. An increased number of lymphocytes has been found in bronchoalveolar lavage fluid 24 hours after provoked exposure to hydrogen fluoride in concentrations similar to those routinely measured in the aluminium industry. ${ }^{24}$

The non-smoking potroom workers did not differ from the control subjects for spirometric values. In fact, their lung function seemed to be well preserved with mean values $>90 \%$ of predicted for both FVC and $\mathrm{FEV}_{1}$. This may primarily reflect a healthy worker selection bias. A preselection of workers without asthmatic symptoms is carried out before employment in Norwegian potrooms. All subjects who want to work in potrooms, must also undergo spirometric screening, and values $>80 \%$ of predicted normal is a prerequisite for being employed. Consequently, subjects with respiratory limitations will never enter the workforce, but workers who develop clinically manifest asthma while employed in the potrooms will be relocated to different work. This selection of healthy workers to the potrooms does, in turn, imply a bias towards a potentially higher occurrence of respiratory disorders in the control subjects who were not originally screened and selected. The fact that we found increased concentrations of exhaled NO in the originally "healthiest" group, should therefore strengthen the significance of the observation.

That potroom workers with asthma-like symptoms did not have reduced spirometric values, may indicate that in this occupational setting such symptoms do not necessarily mean clinically manifest asthma, but rather a mild, subclinical condition. This would also explain why the NO concentrations of potroom workers were not as high as would be expected in a population of true asthmatic subjects. Furthermore, spirometry is probably too crude to detect early signs of asthma in a cross sectional study. Mildly asthmatic subjects have, in general, normal spirometric measurements, and only when inflammation has resulted in sufficient morphological changes to produce manifest obstruction, will $\mathrm{FEV}_{1}$ be reduced. To investigate whether the increased concentrations of $\mathrm{NO}$ found in the exposed subjects did in fact reflect airway inflammation, would have required comparison with methods more sensitive than spirometry-such as induced sputum or bronchoalveolar lavage. Positive correlations with other markers of airway inflammation would have contributed to strengthen the relevance of our findings, but in a large field study it was not possible to perform such complicated test procedures.

The occurrence of asthma-like symptoms was $17 \%$ among the potroom workers and $12 \%$ in the controls. This is higher than the prevalence of asthma in the general population, ${ }^{4}$ and might partly reflect overreporting of symptoms among workers who are regularly screened for airway disorders because of an occupational risk. In the exposed group, we found that subjects who reported asthmalike symptoms had 2.5-fold higher exhaled concentrations of NO than those who reported no symptoms. This strengthens the hypothesis that respiratory symptoms reported by potroom workers do in fact represent airway inflammation as in asthma. Although their symptoms were in all cases mild (which is also reflected by the fact that no subject used inhaled corticosteroids), their exhaled concentrations of NO were significantly increased compared with the control group. Examination of bronchial hyperresponsiveness, which is another marker of airway inflammation known to be associated with potroom exposure, ${ }^{2}$ might also have supported our hypothesis. However, in the present setting where we had to take healthy workers out of their jobs for test procedures, it was unfortunately not possible to carry out time consuming bronchial provocation tests on top of the other tests.

We found that levels of exposure to fluorides and dust as obtained by routine measurements, were neither associated with asthma-like symptoms nor with increased concentrations of NO in exhaled air. The three most likely explanations for this negative finding would be $(a)$ that the measured concentrations (of both fluorides and particulates) lay within a too narrow range and well below the hygienic standards, (b) misclassification of the exposure variable, as it was based on routine measurements and not 
individually obtained measurements, and (c) peak exposures (to fluorides) were not measured. Without a control group, the lack of association between levels of exposure and concentrations of exhaled NO, would have masked the positive association between potroom exposure and exhaled NO. This shows the importance of having a control group for this kind of study.

No association was found between the number of years employed, which was used as a substitute for cumulative exposure, and concentrations of exhaled NO. However, this exposure variable does not take into account different job exposures over the years, and the possibility of a healthy worker effect as well as exposure misclassification is obvious. Consequently, the lack of an association does not exclude the possibility that cumulative exposure may have had an effect on exhaled NO.

Our analyses were primarily carried out on non-smoking subjects, as smokers are known to have low concentrations of exhaled NO. ${ }^{12}{ }^{19}{ }^{20}$ We chose to classify both ex-smokers and never smokers as non-smokers. The reason we did not split smoking habits into three categories, was that the number of never smokers in this industrial population was too small for meaningful analyses to be carried out. In fact, the number of current smokers among potroom workers was so high $(47 \%)$ that it was not possible to recruit a matched control group for smoking habits. The proportion of smokers in our control group recruited from the mechanical workshop and laboratory was $25 \%$. If we had chosen control subjects from the administrative staff, the proportion of smokers would have been $<10 \%$. However, as our aim was to study exhaled NO, we were primarily interested in comparing non-smoking subjects. Exhaled NO is not a useful marker of airway inflammation in smokers, as their concentrations of NO will invariably be decreased due to the effects of smoking itself. ${ }^{19} 20$

To our knowledge, there are no available data on concentrations of exhaled $\mathrm{NO}$ in healthy ex-smokers, only in ex-smokers with chronic obstructive pulmonary disease. ${ }^{25}$ Thus we do not know whether exhaled NO of healthy ex-smokers differs significantly from that of healthy never smokers. It may be speculated that a potential hangover effect of smoking would imply a trend towards lower exhaled NO concentrations in ex-smokers than in never smokers. If so, we might have introduced a bias towards lower NO values by grouping exsmokers with never smokers.

We conclude that exposure to potroom pollutants is associated with increased concentrations of exhaled NO in non-smoking subjects. The NO in exhaled air may be an early marker of early airway inflammation in aluminium potroom workers.

The study was supported by grants from The Norwegian Research Council, Astra Norway, and Hydrogas Norway. We ing the field study, and the employees at the aluminium plant for participating.

1 Abramson MJ, Wlodarczyk JH, Saunders NA, et al. Does aluminum smelting cause lung disease? Am Rev Respir Dis 1989;139:1042-57.

2 Kongerud J, Boe J, Søyseth V, et al. Aluminium potroom asthma: the Norwegian experience. Eur Respir f 1994;7: 165-72.

3 Kongerud J, Samuelsen SO. A longitudinal study of respiratory symptoms in aluminium potroom workers. Am Rev Respir Dis 1991;144:10-16.

4 Bakke P, Baste V, Hanoa R, et al. Prevalence of obstructive lung disease in a general population: relation to occupational title and exposure to some airborne agents. Thorax 1991;46:863-909.

5 Walker TJ. Hygienic aspects of aluminium reduction. In: Hughes JP, ed. Health protection in primary aluminium production. London: International Primary Aluminium Institute, 1978;23-29.

6 Barnes PJ. Nitric oxide and airway diseases. Ann Med 1995; 27:389-93.

7 Kharitonov SA, Yates D, Robbins RA, et al. Increased nitric oxide in exhaled air of asthmatic patients. Lancet 1994;343: 133-5.

8 Kharitonov SA, Wells AU, O'Connor BJ, et al. Elevated levels of exhaled nitric oxide in bronchiectasis. Am F Respir Crit Care Med 1995;151:1889-93.

9 Kharitonov SA, O'Connor BJ, Evans DJ, et al. Allergeninduced late asthmatic reactions are associated with elevation of exhaled nitric oxide. Am $\mathcal{F}$ Respir Crit Care Med tion of exhaled nitric

10 Kharitonov SA, Yates D, Barnes PJ. Increased nitric oxide in exhaled air of normal human subjects with upper exhaled air of normal human subjects with upper

respiratory tract infections. Eur Respir F 1995;8:295-7.
1 Barnes PJ, Kharitonov SA. Exhaled nitric oxide: a new lung function test. Thorax 1996;51:233-7.

12 Kharitonov S, Alving K, Barnes PJ. Exhaled and nasal nitric oxide measurements; recommendations. Eur Respir $\mathcal{F} 1997$; 10:1683-93.

13 Søyseth V, Kongerud J. Prevalence of respiratory disorders among aluminium potroom workers in relation to exposure to fluoride. $\mathrm{Br} \mathcal{F}$ Ind Med 1992;49:25-130.

14 Søyseth V, Kongerud J, Ekstrand J, et al. Relation between exposure to fluoride and bronchial responsiveness in aluminium potroom workers with work-related asthma-like symptoms. Thorax 1994;49:984-9.

15 Kongerud J, Vale JR, Aalen OO. Questionnaire reliability and validity for aluminium potroom workers. Scand $\mathcal{F}$ Work Environ Health 1989;15:364-70.

16 American Thoracic Society. Standardization of spirometry: 1987 update. Am Rev Respir Dis 1987;136:1285-98.

17 Quanjer PhH, Tammeling GJ, Cotes JE, et al. Standardized lung function testing. Eur Respir f 1993;10:1683-93.

18 Henriksen AH, Sue-Chu M, Lingaas-Holmen T, et al. Exhaled and nasal NO levels in allergic rhinitis; relation to sensitization, pollen season and bronchial hyperresponsiveness. Eur Respir F 1999;13:301-6.

19 Kharitonov SA, Robbins RA, Yates D, et al. Acute and chronic effects of cigarette smoking on exhaled nitric oxide. Am $\mathcal{F}$ Respir Crit Care Med 1995;152:609-12.

20 Verleden GM, Dupont LJ, Verpeut AC, et al. The effect of cigarette smoking on exhaled nitric oxide in mild steroid naive asthmatics. Chest 1999;116:59-64.

21 Søyseth V, Kongerud J, Boe J, et al. Bronchial responsiveness and work-related asthma in aluminium potroom workers: and work-related asthma in aluminium potroom workers: 33.

22 Søyseth V, Kongerud J, Haarr D, et al. Relation of exposure to airway irritants in infancy to prevalence of bronchial hyper-responsiveness in schoolchildren. Lancet 1995;345: 217-20.

23 Søyseth V, Kongerud J, Boe J. Allergen sensitization and exposure to irritants in infancy. Allergy 1996;51:719-23.

24 Lund $\mathrm{K}$, Refsnes M, Søstrand P, et al. Inflammatory cells increase in bronchoalveolar fluid following hydrogen fluoride exposure. Am 7 Respir Crit Care Med 1995;151:
A259.

Maziak W, Loukides S, Culpitt S, et al. Exhaled NO in chronic obstructive pulmonary disease. Am $\mathcal{F}$ Respir Crit Care Med 1998;157:998-1002. 